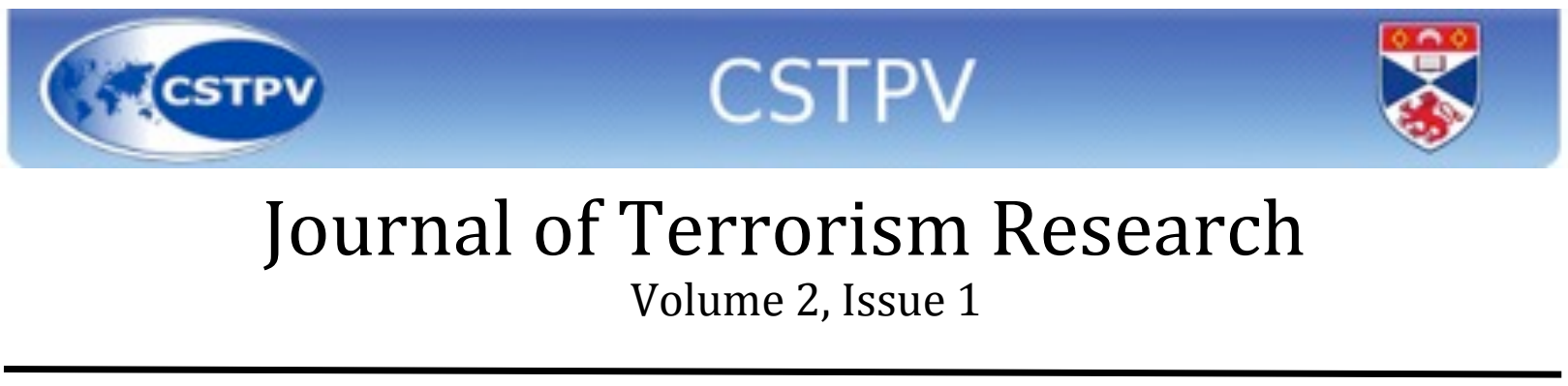

\title{
Opinion Piece - The Need for Situational Awareness in a CBRNE Attack
}

\section{by Jordan Nelms}

Witt Associates

\section{Washington D.C., US}

Six years before the terrorist attacks on the World Trade Center and the Pentagon, and eight years before the United States went to war with Saddam Hussein for his alleged concealment of chemical and biological weapons caches, Japan's Tokyo subway was struck by one of the most vicious terror attacks in modern history. The 1995 Sarin terrorist attack represents an important case study for post-9/11 emergency managers because it highlights the key issues first responders and public health officials face when confronted with a CBRNE (Chemical, Biological, Radiological, Nuclear, Explosive) mass-casualty attack.

The after-action reporting following the Tokyo Sarin attack noted serious deficiencies in the identification of the threat, and the escalating confusion about why so many obviously sick people were coming out of the subway station. First responders arrived on the scene quickly but, because Sarin is an invisible gas, fire and EMS units were unaware that the scene was hot and did not know the nature of the threat they were facing. Although they did an effective job evacuating and getting people out of the subway station, their failure to take precautionary measures specific to a CBRNE attack caused the unnecessary contamination of hundreds of first responders themselves as well as innocent bystanders. Hospitals became a primary decontamination area by default, putting emergency room doctors and other hospital workers and patients also at risk for contamination.

Recognizing these challenges, in 1995 the U.S. Department of Energy embarked on the research and development of an Autonomous Pathogen Detection System (APDS), the purpose of which is to pre-position detection devices in high-threat environments, increasing the situational awareness of first responders and emergency managers dealing with a CBRNE incident.

\section{PROTECTing the Responders - The First Priority}

Sandia National Laboratories initiated testing, in 2000, of an APDS specifically designed to meet the need of U.S. subway systems by simultaneously detecting a number of chemicals, viruses, and toxins. Meanwhile, the Program for Response Operations and Technology Enhancements for Chemical/Biological Terrorism (PROTECT) was being piloted by the Washington Metropolitan Area Transit Authority (WMATA). In 2003, after three years of testing, PROTECT 


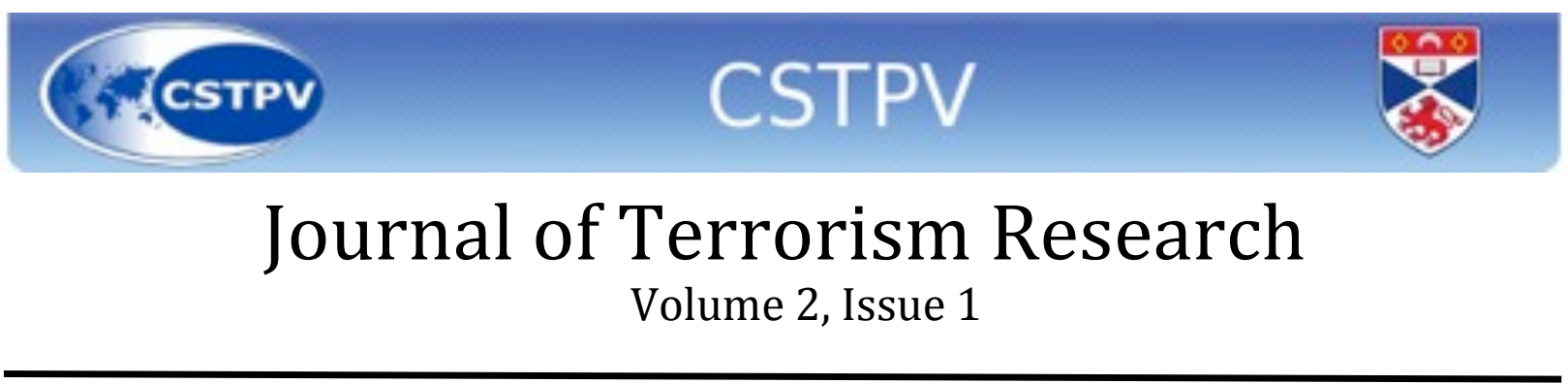

became a permanent program at WMATA, and now operates in over a dozen high-volume stations along the Authority's Metro system.

An important responsibility of an emergency manager is to protect the safety and health of first responders. Increasing the emergency managers' ability to make informed decisions in the face of a CBRNE attack not only has a critical impact on the first responders' ability to save the lives of attack victims, but also protects them from personally becoming victims. The success of the PROTECT program has the potential to become a mainstay in the homeland security programs of other major metropolitan cities. The APDS technology is now well established, and in wide use by the Department of Defense. The PROTECT program, on the other hand, because of its relative infancy and much higher cost, faces considerable barriers before national implementation would be possible.

The fact is that, as in many other homeland security initiatives, federal funding does not match the realistic cost of capability implementation. Nor can these high technology programs be paid for from the subway operators' general funds. A key theme of the DHS (Department of Homeland Security) UASI (Urban Area Security Initiative) and Transit Security Grant programs focuses on the protection of critical infrastructure, including the nation's subway systems. Ninety-six percent of the Transportation Security Administration's Tier I funds awarded to the National Capital Region, and seventy-one percent of the funds awarded to the New York Region, were allocated to infrastructure protection projects. Those projects served as pilot programs for the rollout of many critical technology solutions - and the subway systems of both cities, according to DHS, are at the highest risk of a CBRNE attack. Associations and subway operators are continuing to lobby DHS for additional funding in this area, hoping to expand the PROTECT system beyond Washington, New York, and Boston. It is clear that operators see the benefit in such a system, and understand that the only way to procure the technology is through federal grants.

Subway operators are hopeful that, after the PROTECT program becomes standardized in its technology and implementation requirements, it will be expanded to other major metropolitan cities. At present, however - almost 15 years after the Tokyo Sarin attack, and 11 years since the inception of PROTECT - operators are increasingly anxious to know DHS's intentions for a national rollout. At present they can only hope, though, that after that happens there will be not only clear guidance provided but also the development of the technology standards required and an infusion of follow-on grant funds. 


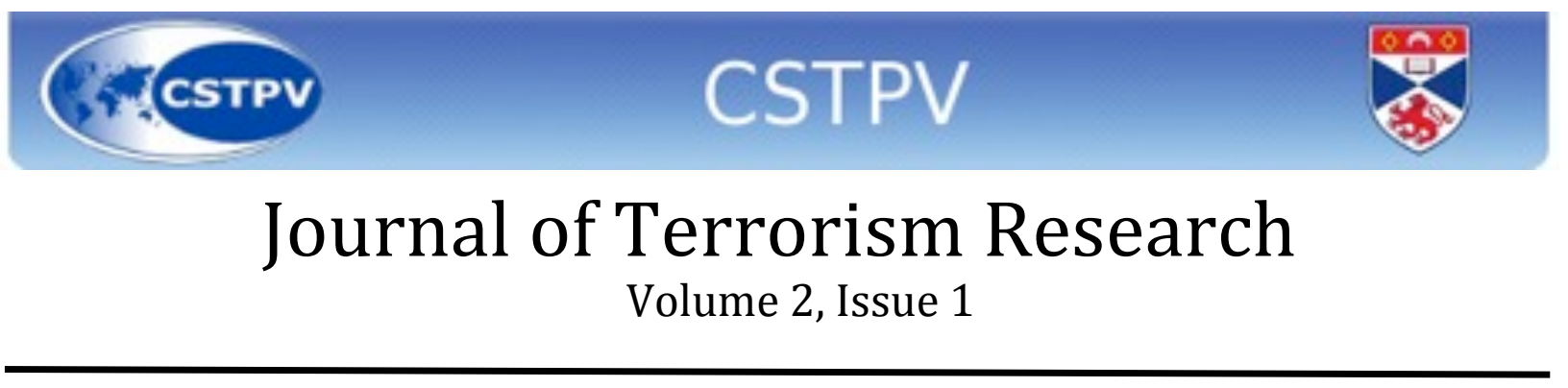

In the competitive grant environment that DHS facilitates, emergency managers, first responders, and subway patrons alike are hopeful that the department's risk-based awards are increased, and the PROTECT system be allowed to proliferate in major cities around the nation.

Jordan Nelms is a homeland security planner for Witt Associates, a Washington DC based consulting firm founded by former U.S. Federal Emergency Management Agency (FEMA) Director James Lee Witt. He has been responsible for providing planning to federal, state and local agencies across the United States, focusing on terrorism and man made disaster preparedness and response. He received his Master of Arts in Global Security Studies from Johns Hopkins University, and is a graduate of the CSTPV Terrorism Certificate program. 